\title{
Video Teleconsultation Service: Who Is Needed to Do What, to Get It Implemented in Daily Care?
}

Jacqueline J.W. Visser, P.T., M.Sc., ${ }^{1}$ J.K.C. Bloo, M.Sc., F.A. Grobbe, M.Sc., ${ }^{2}$ and M.M.R. Vollenbroek-Hutten, Ph.D. ${ }^{1,3}$

${ }^{1}$ Department of Technology Assisted Pain Rehabilitation, Roessingh Research and Development, Enschede, The Netherlands.

${ }^{2}$ Adviseurs voor Organisatiewerk, Driebergen, The Netherlands.

${ }^{3}$ Faculty of Electrical Engineering, Mathematics, and Informatics, University of Twente, Enschede, The Netherlands.

\section{Abstract}

Introduction: In telemedicine, technology is used to deliver services. Because of this, it is expected that various actors other than those involved in traditional care are involved in and need to cooperate, to deliver these services. The aim of this study was to establish a clear understanding of these actors and their roles and interrelationships in the delivery of telemedicine. A video teleconsultation service is used as a study case. Methods: A business modeling approach as described in the Freeband Business Blueprint Method was used. The method brings together the four domains that make up a business model, that is, service, technology, organization, and finance, and covers the integration of these domains. The method uses several multidisciplinary workshops, addressing each of the four domains. Results: Results of the four domains addressed showed that (1) the video teleconsultation service is a store and put-forward video teleconsult for healthcare providers. The service is accepted and has added value for the quality of care. However, the market is small; (2) the technology consists of a secured Internet Web-based application, standard personal computer, broadband Internet connection, and a digital camera; (3) a new role and probably entity, responsible for delivering the integrated service to the healthcare professionals, was identified; and finally (4) financial reimbursement for the service delivery is expected to be most successful when set up through healthcare insurance companies. Pricing needs to account for the fee of healthcare professionals as well as for technical aspects, education, and future innovation. Discussion: Implementation of the video teleconsult service requires multidisciplinary cooperation and integration. Challenging aspects are the small market size and the slow implementation speed, among others. This supports the argument that accumulation of several telemedicine applications is necessary to make it financially feasible for at least some of the actors.

Key words: telecommunications, telemedicine, telehealth, business administration/economics

\section{Introduction}

he aim of integrated care is the provision of comprehensive,
coordinated, and continuous services over an extended
period of time. ${ }^{1}$ Integrated healthcare for chronically ill
patients involves many different healthcare professionals and organizations. Such is especially true for healthcare for children with complex movement disorders. Yet, integrated care is prone to communication gaps. These communication gaps and poor synchronization result in suboptimal healthcare delivery. ${ }^{2}$ Van der Salm et al. $^{3}$ also showed that coordination, communication, and synchronization of (transmural) treatment is insufficient for children with complex movement disorders.

Many believe that telemedicine could bring a major improvement to the provision of future healthcare. ${ }^{4}$ However, although many promising telehealth projects deliver a working research and development (R\&D) prototype, they do not succeed in actual deployment. The focus is often on proving the capabilities and efficacy of prototypes by means of technological projects and clinical user 
studies, but, despite the fact that the results are often encouraging, most telehealth initiatives do not survive the research phase. ${ }^{5-7}$ As a consequence, the established sector still mainly relies on its traditional processes of healthcare delivery. ${ }^{8}$ Apparently, there is a large gap between R\&D prototypes and the actual large-scale deployment. Successful large-scale implementation, however, also requires consideration of financial arrangements, organizational issues, and governmental policy and legislation issues. ${ }^{5,9,10}$ It is hypothesized that early identification of the stakeholders and their roles and interrelationships in the potential business could help to create a "shared vision and understanding" and also supports acceleration in the telehealth market. ${ }^{10}$ Therefore, the aim of this study was to clearly understand these various stakeholders, their roles, as well as the way they need to cooperate for delivery of telemedicine services. In this study, a video teleconsultation service is used as a case study.

\section{Methods}

\section{FRAMEWORK FOR BUSINESS MODEL}

The method applied was a business modeling approach. Within the business modeling approach, the Freeband Business Blueprint Method was used. ${ }^{11}$ This method is especially suited for the development of viable business models for (mobile) information and communication technology (ICT) services. Using the acronym STOF, this method brings together four domains that make up the business model: the service $(\mathrm{S})$ domain, the technology $(\mathrm{T})$ domain, the organizational
(0) domain, and the financial (F) domain. In short, the service domain holds the service concept, the market, and value proposition of the service. The technology domain includes the technical functions and the architecture needed to realize that value proposition. The organizational domain concerns agreements with respect to cooperation between the organizations to deliver that value proposition. The financial domain includes costs, investments, revenues, risks, and furthermore, agreements on how to divide them among the organizations. Figure 1 shows the business model framework.

\section{WORKSHOPS AND PARTICIPANTS}

According to the method, several multidisciplinary workshops were organized, addressing each of the four domains and the integration of those domains. A core group of participants with different backgrounds participated in each workshop. This group consisted of several healthcare professionals, people with knowledge of information and communication technology, people who researched and developed the video teleconsultation service, business model experts, a consultant in organizational aspects and cooperation, and a consultant in the field of innovation in healthcare. In addition, a healthcare insurance company participated in the financial aspects. Participants were invited depending on which domains were being addressed in the workshops.

The typical setting of the workshops was that two people facilitated the workshops, one led the group discussions and the other wrote down comments and answers. Each domain addressed was divided into subcategories, and small assignments were given to subgroups of participants to describe each subcategory. Results were discussed in plenary to come to a common vision of each domain and the integration of all domains.

The subcategories of the service domain were the actual service, the client and market size, added value, disadvantages, and alternatives. The technology domain was described by means of infrastructure, end user requirements, and architecture. The organization domain addressed the roles, stakeholders, and agreement concerning cooperation. In the financial domain, the reimbursement, investments costs, benefits, and risks were defined.

\section{Results THE SERVICE}

The video teleconsultation service is a standardized asynchronous question and answer consultation ser-

Fig. 1. Business model framework. 
vice for healthcare professionals who are working with children with postural and movement disorders. Asynchronous mode allows healthcare professionals to schedule their own agenda and therefore make the service easily accessible.

Video makes it possible to show the clinical movement disorders directly to the consultant regardless the distance. Additional patient information must accompany the video fragments and be submitted using a standardized template based on protocol. This requires video handling and computer skills as well as training of the professionals in the use of the application.

\section{CLIENTS AND MARKET}

The target users are networks of healthcare professionals such as physiotherapists, pediatric physicians, rehabilitation physicians, occupational therapists, orthopedic surgeons, and neurologists who are working together with patients who have posture and movement disorders. Table 1 shows the market for healthcare professionals in the field of posture and movement disorders. This overview shows that physiotherapists account for $\sim 80 \%$ of that total market. It is expected that the physiotherapist will pose the questions and physicians will be the answering professionals. Earlier research showed that implementation in such a network of healthcare professionals is rather time consuming. ${ }^{12}$ Therefore, implementation speed will be slow.

\section{ADDED VALUE}

The added value of the service is that it improves the quality of care through better cooperation and synchronizing of integrated care.

Table 1. Total Market of Healthcare Professionals in Posture and Movement Disorders

\begin{tabular}{l|c}
\multicolumn{1}{c|}{ DISCIPLINE } & NUMBER \\
\hline Pediatric physicians & 1,190 \\
\hline Physiotherapists & 20,000 \\
\hline Occupational therapists & 3,500 \\
\hline Rehabilitation physicians & 370 \\
\hline Orthopedic surgeons & 531 \\
\hline Neurologists & 770 \\
\hline Total possible users & 26,361 \\
\hline
\end{tabular}

Experts' opinion from a different setting can be incorporated in treatment planning without physical referral of the patient. Therefore, patients can stay in (less expensive) primary care longer, with support of expert knowledge from (more expensive) secondary or tertiary care. If necessary, physical referrals can be made more effectively after the video teleconsult. Parents do not need to take off work to visit an expert or medical specialist. The video is taped in the child's familiar environment; therefore, the child will demonstrate the movement patterns concerned. This behavior may not be demonstrated by a (young) child in the unknown environment of a specialist's office. From video, the specialist is able to observe that very specific behavior. Each teleconsult may also increase knowledge of the healthcare professionals and therefore have a learning effect.

Besides, although focused on children with postural and movement disorders, the service is not limited to this population. Focus on, for example, the adult patient rehabilitation populations can be an option as well.

\section{DISADVANTAGES}

Beside all the mentioned advantages, healthcare professionals may notice some disadvantages of video teleconsultation such as missing face-to-face contact with the patient or investment in technical requirements and education including the extra costs this brings about.

\section{ALTERNATIVES}

Alternatives for this service are mailing a video (on compact disc) by post to the specialist, with the disadvantage of being insecure. Other ways of consultation such as e-mail, telephone, or mail contact do not give the information with the quality of movement given by video.

\section{TECHNOLOGY}

Infrastructure. The infrastructure consists of a Web application. To ensure privacy and security, the infrastructure provides access via a secured socked layer and the database meets the policy and legislation requirements for medical record keeping. Each end user, the healthcare professional, can access the server by a personal login code. An easily accessible helpdesk service for technical questions and support needs to be available to the end user.

End user requirements. To be able to perform consultations the end users require a personal computer, with hardware and software for 
video editing, broadband Internet connection, and a digital video camera connected to the computer. All these end user requirements are commonly available.

Architecture. For large-scale implementation, integration with other patient information technology systems should be possible, for example, integration with professional administrative systems that allow verification of mandatory healthcare insurance or integration with other systems for exchange of patient medical or clinical information. Therefore, service-oriented architecture may need to be developed.

\section{ORGANIZATION}

Stakeholders and roles. Table 2 shows the stakeholders and their roles needed for the delivery of the video teleconsultation service and also the relationships they have with each other. A stakeholder is defined as a person, group, organization, or system that affects or can be affected by an organization's action. Roles are the functions or duties that need to be performed by a stakeholder.

The currently identified stakeholders are the healthcare professional, patient, insurance company, technology provider, and government. However, it became evident during the workshops that video teleconsultation would only integrate in the actual clinical practice when the different stakeholders combine their strengths and work together. As the different stakeholders are typically not used to cooperate with each other, this needs to be organized. For example, a very important finding coming out of the workshop is that an individual healthcare professional willing to use the video teleconsultation service may not be able to or willing to arrange some aspects such as technology or negotiation with insurance companies about the tariffs by himself. Therefore, another role, namely the service provider, emerged out of the workshop as an important new one. This role focuses on the delivery of the integrated service to the healthcare professionals.

Agreements concerning cooperation. During the integration workshop, the relationships between the different stakeholders toward each other and the service provider was defined and worked out in a potential business model for the video teleconsultation service. Figure 2 shows this potential business model and these relationships, including the financial flow toward and from the service provider.

According to this business model, (a network of) healthcare professionals who want to use the video teleconsultation service during treatment of their patients contact the service provider who arranges for the education, the technology, and the helpdesk and takes care of the billing and paying. As in The Netherlands, tariffs for healthcare

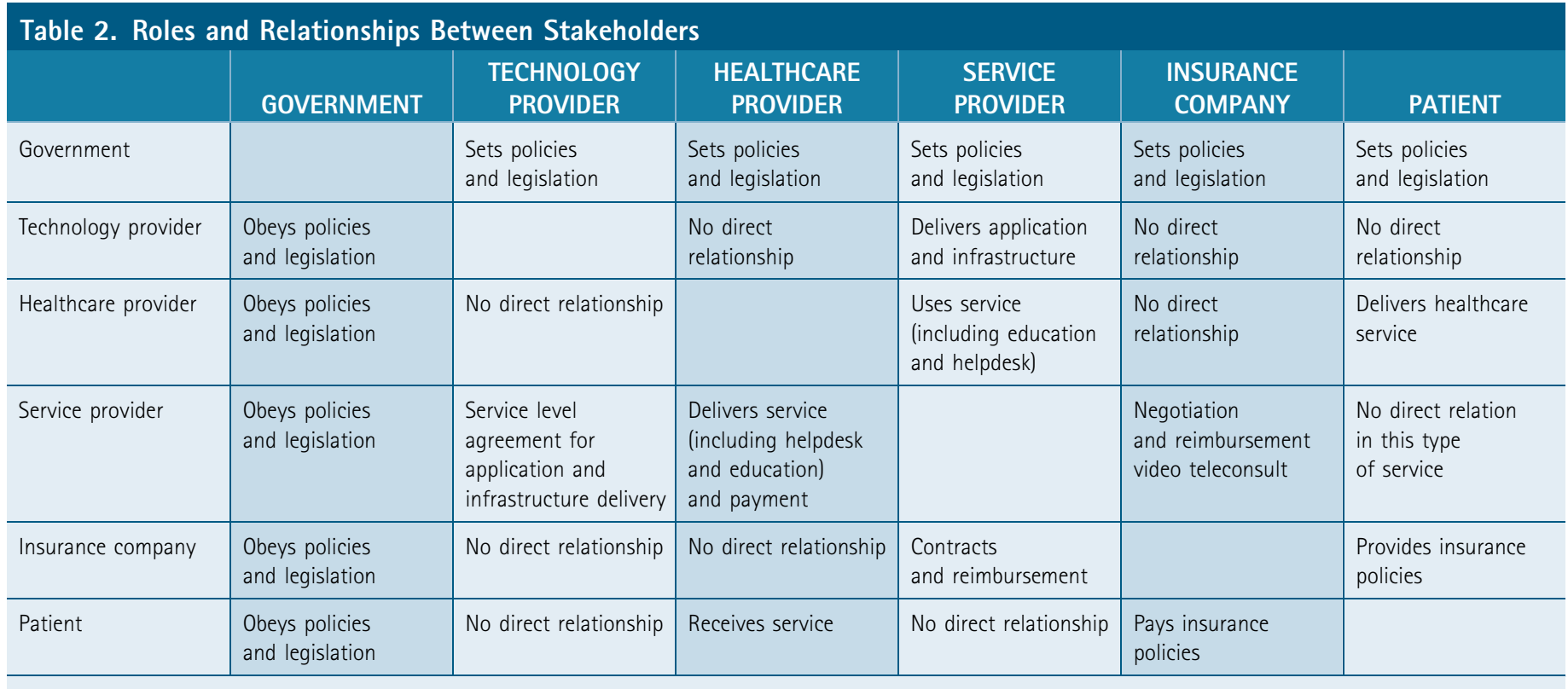




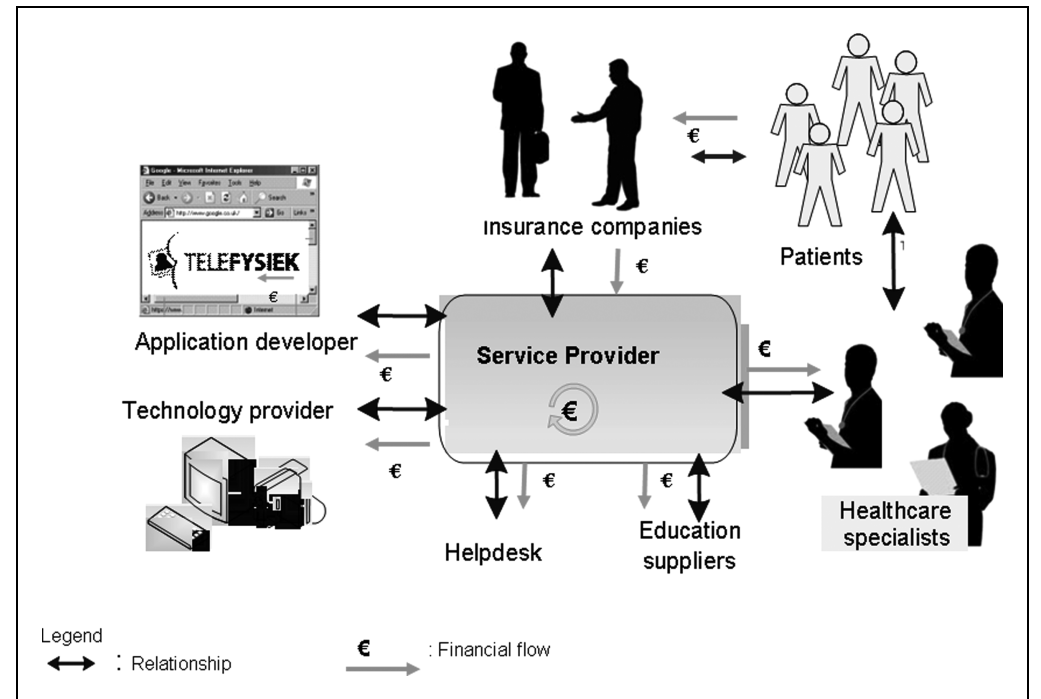

Fig. 2. Potential business model for video teleconsultation.

services can only be negotiated by healthcare institutes, it is most obvious that the service provider role is performed by an entity that has the right status for doing this.

\section{FINANCE}

Reimbursement. Insurance of national healthcare is obligatory to every citizen in The Netherlands. The Dutch healthcare system is organized in primary, secondary, and tertiary care. The primary care, where most physical therapy is provided, is a competitive market with price negotiations with healthcare insurance companies. Secondary care (general hospitals) and tertiary care (rehabilitation centers and university hospitals) settings have regulated tariffs established by the government. The reimbursement for the video teleconsultation needs to fit into these different pricing strategies.

Both building and answering a video teleconsult requires the time and the clinical reasoning skills of the healthcare professionals. To be viable for everyday healthcare practice, healthcare insurance companies need to consider telemedicine as a form of healthcare delivery that is covered by their insurance policies. This is currently the case in The Netherlands.

Pricing. It became clear that with respect to pricing of telehealthcare not only the fee for the healthcare professional needs to be included but also reimbursements for aspects such as technical support, future innovation, and education needs to be incorporated.

\section{Discussion}

The aim of this study was to come to a clear understanding of various stakeholders and their roles and interrelationship in a potential business model for a telemedicine service, in this case a video teleconsultation service. The main results of this study showed that besides already existing stakeholders and roles, a new role and entity, namely the integration role of the service provider, is needed. Using this business modeling approach gave insight into the flow of funds and the central role of the service provider. Financial reimbursement for the service delivery is expected to be most successful when set up through healthcare insurance companies. Pricing needs not only account for the fee of the healthcare professional but also for the roles of the other stakeholders involved.

Understanding of stakeholders and their roles in a potential business model also gave a better insight on how to come to a real large-scale implementation in daily healthcare. The domains of the Freeband Business Blueprint Model $^{11}$ match quite well to the five determinants important for successful implementation as described by Broens et al. ${ }^{10}$ According to Broens, acceptance, technology, finance, organization, policy, and legislation should all be addressed to come to a successful implementation. Acceptance is the only aspect not addressed in this study but has been most often addressed ${ }^{13,14}$ already in the early development phase and is as such also done for the current application as described by Visser et al. ${ }^{12}$ and Engbers et al. ${ }^{15}$

In all domains, major or minor challenges exist to realize largescale implementation. In more detail, the challenges facing for implementation of the service appeared to be the market size and the slow implementation speed. To make telemedicine services feasible, a large market is needed. However, the market for the case of this study is not that large. Given the fact that implementation occurs via a network of professionals and as such is rather time consuming, ${ }^{12}$ it is hypothesized that the video teleconsult as a single telemedicine application will not be viable in short time. ${ }^{16}$ This suggests that various telemedicine services probably will need to be combined.

\section{THE CHALLENGES FACING TECHNOLOGY}

Currently, the Dutch government is working on the realization of a national electronic patient record, ${ }^{17,18}$ with the intention to exchange medical information between general practitioner, pharmacy, and hospitals. ${ }^{19}$ Therefore, in anticipation of these developments it is important that service-oriented architecture should not be developed solely as a technical platform for several telemedicine applications, 
but should also allow integration with other databases such as patient healthcare insurance information.

\section{THE CHALLENGE FOR GETTING THE SERVICE ORGANIZED}

Results showed that various stakeholders from different domains are required and they need to cooperate in order to be able to deliver this video teleconsultation service in everyday care. In line with the components of telemedicine and telehealth programs as described by Weinstein et al., ${ }^{20}$ the most important stakeholders identified are patients, healthcare professionals, technology providers, insurance companies, and the government. This study made clear that although most stakeholders already exist, they are performing their roles independent from each other. Cooperation among these stakeholders is neither obvious nor in current practice, but needs to be arranged. To enable this cooperation, a so-called service provider role that focuses on integration and organization, establishment of service level agreements, negotiation with healthcare insurance companies, and billing is needed. Potential organizations for this coordinating role can be a technology provider, for example, the Arizona Telemedicine Program, which is based on an application service provider concept, ${ }^{21}$ a healthcare institute that, in The Netherlands, has the right status for negotiation with healthcare insurance companies and will feel most comfortable delivering healthcare, or a newly created spin off company born out of a knowledge institute that can focus on application development, education, and provision of evidence-based protocols.

\section{THE CHALLENGE FOR THE FINANCING}

Currently when a patient in The Netherlands is referred from primary to secondary or tertiary care, different billing systems need to be addressed to bill for the existing healthcare problem. A transmural fee should overcome this problem, so consultation can be delivered equally across primary, secondary, or tertiary settings. Appropriate tariffs to reimburse healthcare professionals as well as supporting technology, education, and future innovation should be incorporated in pricing of the service.

Even though not directly related to the business model, the facilitating role of the government is needed to overcome some of the technical and financial barriers, by developing policy and procedures. Also legal issues, such as health professional identification, need to be addressed.

All these challenges in implementation cannot be overcome all at once. Therefore, an iterative process with constant updates and improvement on all domains seems a realistic strategy to close the gap between R\&D prototypes and actual large-scale deployment of telehealth.
This study describes the different actors and roles needed for implementation of a telemedicine services. The next step is developing a quantitative business model for the different implementation scenarios described. Based on that, choices for the accumulation of services can be made and proper deployment strategies can be developed.

\section{METHODOLOGICAL CONSIDERATIONS}

This study focused on the Dutch situation. We all know that differences in healthcare insurance system, rules, and regulations exist among the European countries. For instance, the European project Myotel $^{22}$ showed that in The Netherlands care provision is reimbursement based on a fixed price for one complete treatment, regardless of the time it takes (and in that case indirectly stimulating treatment methods to become more efficient), whereas in the other countries, care is reimbursed on an hourly basis (and in that case not stimulating to increased efficiency). Besides, there is difference in state influence on the healthcare system, which is quite low in The Netherlands compared with the other countries, whereas Sweden characterizes itself by having regulation at a very local level. However, these differences are expected to not have an effect on the business models in terms of the roles and entities identified and needed, and as such the business model presented here can be generalized. These differences do influence the actual implementation in various countries and need to be considered in actual deployment strategies.

\section{Conclusions}

Video teleconsultation as a service is promising and has the potential to optimize healthcare processes. However, implementation is challenging because of the necessary but not spontaneously emerging multidisciplinary cooperation, as well as the new roles and probably the new entities that are needed. In addition, the rather small market size as well as rather low implementation speed is adding to this challenge when considering only this application. On the basis of this it is concluded that telemedicine applications need to be accumulated to make telemedicine services financially feasible for at least some of the actors.

\section{Acknowledgments}

This project was funded by Teletoco, the province of Overijssel, and Innovatie Centrum Revalidatie Technology. This work was undertaken within the project "Telefysiek: Opschaling van het VideoTeleconsult in de revalidatie zorg; de patiënt beter in beeld" [Telefysiek: Video Teleconsultation in rehabilitation, a better view of 


\section{VIDEO CONSULTATION POTENTIAL BUSINESS MODEL}

the patient] with conjoint financial support from "Het actie programma Maatschappelijke sectoren \& ICT," an initiative from six federal governments, and the participating organizations.

\section{Disclosure Statement}

No competing financial interests exist.

\section{REFERENCES}

1. Institute of Medicine. Crossing the quality Chas: A new health system for the $21^{\text {st }}$ century. Washington, DC: National Academy Press, 2001.

2. Gulmans J, Vollenbroek-Hutten MMR, van Gemert-Pijnen JEWC, van Harten WH. Evaluating quality of patient care communication in integrated care settings: A mixed method approach. Int J Qual Health Care 2007:19:281-288.

3. Van der Salm A, Van Harten WH, Maathuis CGB. Ketenkwaliteit Cerebrale Parese Zorg; Een beschrijving van de cerebrale parese zorg en mogelijke verbeteringen hierin [Quality of the cerebral palsy care chain]. Progress 2001;8. ISBN 90-75452-19-5. (in Dutch).

4. Hjelm NM. Benefits and drawbacks of telemedicine. J Telemed Telecare 2005;11:60-70.

5. Tanriverdi $H$, lacono CS. Diffusion of telemedicine: A knowledge barrier perspective. Telemed J 1999;5:223-244.

6. Barlow J, Bayer S, Curry R. Implementing complex innovations in fluid multistakeholder environments: Experience of "telecare." Technovation 2006;26:396-406

7. Alemi F. Management matters: Technology succeeds when management innovates. Front Health Serv Manage 2000;17:17-30.

8. Christensen $\mathrm{CM}$, Bohmer R, Kenagy J. Will disruptive innovations cure healthcare? Harv Bus Rev 2000;78:102-112.

9. Berg M. Patient care information systems and healthcare work: A sociotechnical approach. Int J Med Inf 1999;55:87-101.

10. Broens THF, Huis in 't Veld MHA, Vollenbroek-Hutten MMR, Hermens HJ, van Halteren A, Nieuwenhuis LM. Determinants for successful telemedicine implementations: A literature study. J Telemed Telecare 2007;13:303-309.

11. Haaker T, Oerlemans K, Steen M, de Vos H. Freeband Business Blueprint Method Handbook for successful cooperation in the development and exploitation of innovative (mobile) ICT-services. Enschede, The Netherlands: Telematica Institute, 2004

12. Visser JJW, Bloo JKC, Grobbe FA, Vollenbroek-Hutten MMR. Implementation of a broadband video consultation service for children with posture and movement disorders. J Telemed Telecare 2009;15:269-274.

13. Whitten $P$, Love $B$. Patient and provider satisfaction with the use of telemedicine: Overview and rationale for cautious enthusiasm. J Postgrad Med 2005;51:294-300.
14. Venkatesh V, Morris MG, Davis GB, Davis FD. User Acceptance of information technology: Toward a unified view. MIS O 2003;27:425-478.

15. Engbers L, Bloo H, Kleissen R, Spoelstra J, Vollenbroek-Hutten M. Development of a teleconsultation system for communication between physiotherapists concerning children with complex movement and postural disorders. J Telemed Telecare 2003;9:339-343.

16. Business model Telefysi, Teletoco WP1, Version 1.0 (Dutch), July 2007. Available at www.nederlandbreedbandland.nl/uploaded/FILES/htmlcontent/business\% 20model\%20telefysi_final\%20v\%201.pdf (last accessed June 25, 2009).

17. de Graaf JC, Vlug AE, van Boven GJ. Dutch virtual integration of healthcare information. Methods Inf Med 2007;46:458-462.

18. Van der Reis L. Lessons for the U.S. from The Netherlands National Electronic Medical Records System. e-Health Int J 2009;5:35-38.

19. Documenten en publicaties/Voortgangsrapportage elektronisch patienten dossier 09-02-2010 [Progress Report Electronic Medical Patient Records. Minister of Health Care, Well-Being, and Sports]. Available at www.minvws.nl/ dossiers/electronisch-patienten-dossier/ (last accessed May 7, 2010). (in Dutch).

20. Weinstein RS, Lopez AM, Krupinski EA, Beinar SJ, Hocomb M, McNeely RA, Latifi $\mathrm{R}$, Barker G. Current principles and practices of telemedicine and e-health. In:

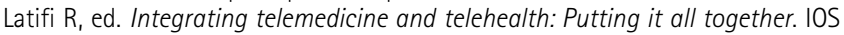
Press, 2008;23-38. ISBN 987-1-58603-806-9.

21. Barker GP, Krupinski EA, McNeely RA, Holcomb MJ, Lopez AM, Weinstein RS. The Arizona Telemedicine Program business model. J Telemed Telecare 2005;11:397-402.

22. www.myotel.eu/projectdetails/Workpackages3and4 (last accessed December 9, 2009)

Address correspondence to: Jacqueline J.W. Visser, P.T., M.Sc. Department of Technology Assisted Pain Rehabilitation Roessingh Research and Development Roessinghsbleekweg 33B

Enschede

Overijssel 7522AH The Netherlands

E-mail: j.visser@rrd.nl

Received: July 10, 2009

Revised: October 12, 2009

Accepted: October 21, 2009 